\title{
Influence of methanol and water extracts of orange peel on stability of refined palm kernel oil
}

\author{
J. O. Arawande ${ }^{1}$, I. A. Amoo ${ }^{2}$ and L. Lajide ${ }^{2}$ \\ ${ }^{1}$ Department of Science Laboratory Technology, Rufus Giwa Polytechnic P.M.B. 1019 Owo, Ondo-State, Nigeri \\ ${ }^{2}$ Department of Chemistry, Federal University of Technology P.M.B. 704 Akure, Ondo-State, Nigeria
}

\begin{abstract}
The antioxidative effect of methanol and water orange peel extracts on Refined Palm Kernel Oil (RPKO) stored for twelve months at room temperature $\left(27^{\circ} \mathrm{C}-33^{\circ} \mathrm{C}\right)$ was determined by monitoring the colour, refractive index, free fatty acid (FFA), acid value (AV) and peroxide value (PV). The oil was dosed with different concentrations (200 ppm to $1000 \mathrm{ppm})$ of the extracts and butylatedhydroxytoluene (BHT) (Cone. $200 \mathrm{ppm}$. The colour and refractive index of RPKO containing the extracts ranged between 11.0-13.0 units and 1.458-1.460 respectively whereas the colour and refractive index of RPKO with no additive $(0 \mathrm{ppm})$ and $200 \mathrm{ppm}$ BHT were 10.0 units and 1.460 accordingly. Free fathy acid (FFA) and acid value (AV) of RPKO containing methanol and water orange peel extracts were lower than RPKO containing $200 \mathrm{ppm}$ BHT and they were significantly different at $\mathrm{P}<0.05$ from RPKO that contained no additive (0 ppm). PV of RPKO containing additives were slightly lower than PV of RPKO that contained no additive but they were not significantly different at $\mathrm{P}<0.05$. The methanol and water orange peel extracts are more effective in combating hydrolytic rancidity than oxidative rancidity of RPKO. The methanol and water orange peel extracts have better antioxidant activity than butylatedhydroxytoluene
\end{abstract}

Keywords: Orange peel extracts; Butylatedhydroxytoluene; Refined palm kernel oil; Stability; Quality characteristics

Introduction

Fats and oils are important part of human diets and over $90 \%$ of lipid production is used as food or ingredient in food production (More, 1990). Lipids contain higher energy than other classes of food (carbohydrates and protein). Generally, fats and oils are sources of essential fatty acids that are of great importance to several metabolic functions in the body. It equally serves as transport medium for fat soluble vitamins (A, D, E and K) which are necessary for proper maintenance of health in both human and animal bodies (Salma and Tranveer, 2005). Hydrolysis is caused by chemical action prompted by factors such as heat or presence of water or enzymatic lipase while oxidation is mainly concerned with the unsaturated fatty acids resulting to characteristic unfavourable off-flavours and odour of lipids which invariably reduces the nutritional quality of foods (Gunstone and Norris, 1983; Navar, 1996; Madhavi et al. 1996; Hamilton et al., 1997).

Refined palm kernel oil is an edible oil obtained from kernels or seeds of African oil palm (Elaeis guineensis). The oil palm kernel contained about $45-50 \%$ oil content (Anomymous, 2011). The crude oil is extracted mechanically by pressing or chemically by using solvent (hexane) after processing the kernels in such away that its surface area have increased
(Bernardini, 1973). Thereafter, the crude oil is refined either by chemical or physical processes involving degumming, neutralization, bleaching and deodourization (Ihekoronye and Ngoddy, 1985; Arawande and Seyifunmi, 2010). Refined palm kernel oil is one of the cheapest vegetable oils in Nigeria and due to its cheapness, it is widely consumed by poor Nigerians. In most cases, it is bought in larger quantity when it is abundantly available due to its low buying price at this time.The oil is stored and sold when the selling price has gone up after six months or more. And during the storage period a lot of unpalatable organoleptic changes would have taken place which posess health risk to the consumers of such oil. Hence the need to prevent oil rancidity by adding antioxidants becomes inevitable.

The uses of synthentic chemical substances in combating or delaying oil rancidity have been reported (Carrasquero et al. 1998; Enrol et al. 2004). Such chemical substances are butylatedhydroxytoluene (BHT), butylatedhydroxyanisole (BHA), propylgallate (PG), tertiary butylatedhydroquinone (TBHQ) and citric acid. Although they are found effective at very low concentrations but they are not safe owing to their toxicity, carcinogenicity and mutagenicity (Maleck, 2002; Murkovic, 2003; Rehab, 2010). This now necessitates

*Corresponding author: E-mail: joawande1@yahoo.com 
provoking interest in searching for safer means of natural antioxidants of plant origin that will have the same or higher potency with the synthetic antioxidants in preventing both oxidative and hydrolytic rancidity of edible oils. The use of various plant extracts as antioxidants or preservative has been documented and reported by researchers (Frankel, 1996; Wanasundara and Shahidi, 1998; Farag et al. 2003; Farag et al. 2006; Arawande and Abitogun, 2009).

Sweet orange peel is basically one of the agricultural wastes that hardly can any Nigerian eats it, though the peel has been reported that it contains a lot of phytochemicals such as ascorbic acid, flavonoids and vitamin $\mathrm{A}$ which are of immense importance to healthy living (Anonymous, 2011).Most of these natural antioxidants found in plants are always coloured or pigmented (carotenoids, chlorophyll, etc) (Oboh and Rocha, 2006); therefore the yellow colour in ripped orange peel suggests that it will be rich in phytochemical antioxidants that can be extracted by suitable solvents. The aim of this work is to investigate the effect of methanol and water extracts of ripped orange peel at varying concentrations (200 ppm - $1000 \mathrm{ppm}$ ) on the colour, refractive index, free fatty acid, acid value and peroxide value of refined palm kernel oil stored in white transparent plastic containers and to compare their antioxidative effect with that of butylatedhydroxytoluene (BHT).

\section{Materials and methods}

\section{Sources of materials}

Orange fruits were purchased from a local farmer at Utelu camp, Iyere, Owo, Ondo-State, Nigeria. The refined palm kernel oil was obtained before being fortified with vitamin A at JOF Ideal Family Farms Limited, Owo, Ondo-State, Nigeria.

\section{Preparation and extraction of orange peel}

Orange fruits were peeled with hands and knife, rinsed with water, chopped into smaller pieces for easy sun drying. The dried peel was ground using electric blending machine and it was sieved with $40 \mathrm{~mm}$ mesh size. The sample was packed into a black polyethene bag prior to extraction.

Twenty gram of the sample was weighed into two cleaned and dried reagent bottles; and $200 \mathrm{~mL}$ of each solvent (methanol and water) was separately added to each bottle and left for 72 hours during which it was intermittently shaken on a shaking orbit machine. The mixture was filtered through a $0.45 \mu \mathrm{m}$ Nylon membrane filter. The extracts were evaporated to dryness under reduced pressure at $40^{\circ} \mathrm{C}$ by a rotary evaporator (Amir et al. 2005; Arawande and Komolafe, 2010).

\section{Addition of additives to refined palm kernel oil}

Methanol and water extracts of orange peel at concentrations of $200 \mathrm{ppm}(0.02 \mathrm{~g}$ per $100 \mathrm{ml}$ oil $)$ to $1000 \mathrm{ppm}(0.10 \mathrm{~g}$ per $100 \mathrm{ml}$ oil) were separately added to Refined palm kernel oil (RPKO) contained in white transparent plastic bottles of equal capacity and they were thoroughly shaken for proper mixing. RPKO containing $200 \mathrm{ppm}$ BHT $(0.02 \mathrm{~g}$ per $100 \mathrm{ml}$ oil) and that which contained no additive ( $0 \mathrm{ppm}$ (control)) were also set- up. Each container was appropriately labeled and stored in an open place at room temperature ranging from $27^{\circ} \mathrm{C}$ to $33^{\circ} \mathrm{C}$.

\section{Physical and chemical analysis}

The colour of the oil sample was determined as described by AOCS 2004 using Lovibond Tintometer (Model 520). The refractive index was also determined using Abbe's Refractometer at $40^{\circ} \mathrm{C}$ (AOCS, 2004). Thereafter, the free fatty acid (FFA), acid value (AV) and peroxide value (PV) of each oil sample were monitored monthly using standard method of analysis (AOCS, 2004) for a period of twelve months.

\section{Statistical analysis}

The results (except colour and refractive index) were compared by one-way analysis of variance (one-way ANOVA) to test for significant difference. Means of the group were compared using Duncan Multiple Range Test (DMRT) (SAS, 2002).

\section{Results and discussion}

Table I reveals changes in colour and refractive index of refined palm kernel oil stored with varying concentration of methanol and water orange peel extracts and 200 ppm BHT. Colour and refractive index are very important physical characteristics for the assessment of edible oils. The addition of additives (methanol orange peel extract (MOPE) and water orange peel extract (WOPE) increased the colour units of refined palm kernel oil (RPKO) by 1 to 3 units when compared with the colour of RPKO that contained no additive $(0 \mathrm{ppm})$. RPKO containing $200 \mathrm{ppm}$ to $1000 \mathrm{ppm}$ MOPE and WOPE had colour units ranged from 11.0 to 13.0 units whereas RPKO containing $200 \mathrm{ppm}$ BHT and the control $(0 \mathrm{ppm})$ had colour of 10.0 units. The lower the colour unit, the more acceptable and attractive the oil becomes. RPKO containing both extracts had colour unit slightly higher than the control but still with acceptable limit (15.0 units maximum) recommended by Standards Organization of Nigeria for refined palm kernel oil (Anomymous, 2000). The addition of WOPE and MOPE at varying concentrations to RPKO did not reflect that the oil was adulterated because the refractive index of those oil samples had approximately the same value (1.458-1.460) with the control $(0 \mathrm{ppm})$ and RPKO containing 200 ppm BHT (1.460). 
Figure I. depicts free fatty acid (FFA) of RPKO stored with methanol orange peel (MOP) extract and butylatedhydroxytoluene (BHT) for twelve months. It was observed that RPKO containing 200 ppm to 1000 ppm MOP extract had lower FFA values than oil sample containing 200 ppm BHT in the first nine months of storage. As the concentration of the extract increases, the FFA of RPKO gradually decreases. The FFA of oil containing MOP extract and $200 \mathrm{ppm}$ BHT was lower than FFA of oil which contained no additive ( $0 \mathrm{ppm}$ (control)). Figure II. reveals free fatty acid (FFA) of RPKO stored with water orange peel (WOP) extract and butylatedhydroxytoluene (BHT) for twelve months. The FFA of oil sample which contained WOP extract and 200 ppm BHT was lower than FFA of oil sample that contained no additive. In the first nine months of storage,

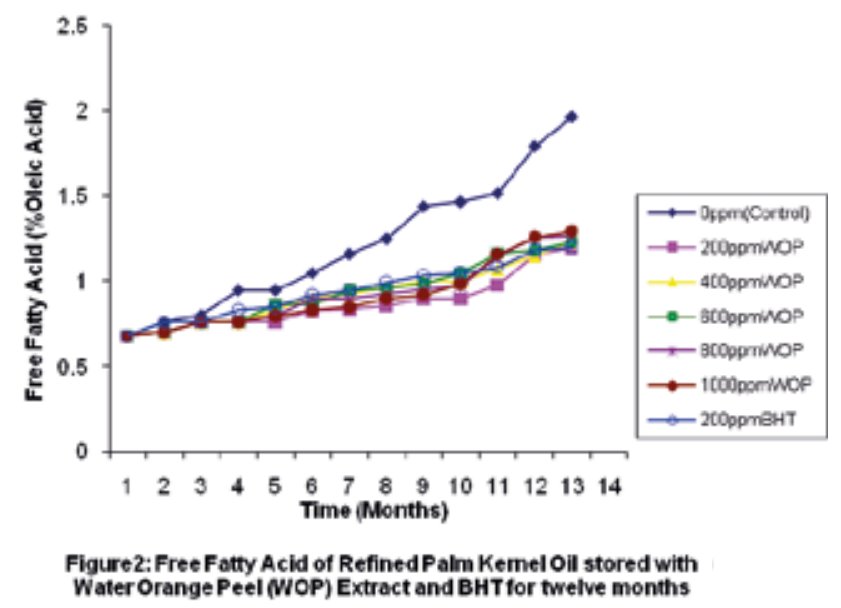

Table I: Changes in colour and refractive index of refined palm kernel oil stored with varying concentration of methanol and water orange peel extracts and 200 ppm BHT.

\begin{tabular}{lcc}
\hline Concentration of Additive & Colour(Units) in 1 inch cell & Refractive Index at $40^{\circ} \mathrm{C}$ \\
\hline 0 ppm (No additive) & $1 \mathrm{R}+5 \mathrm{Y}=10.0$ & 1.460 \\
$200 \mathrm{ppm}$ MOPE & $1 \mathrm{R}+6 \mathrm{Y}=11.0$ & 1.459 \\
$400 \mathrm{ppm}$ MOPE & $1.2 \mathrm{R}+6 \mathrm{Y}=12.0$ & 1.460 \\
$600 \mathrm{ppm}$ MOPE & $1.2 \mathrm{R}+7 \mathrm{Y}=13.0$ & 1.460 \\
$800 \mathrm{ppm}$ MOPE & $1 \mathrm{R}+6 \mathrm{Y}=11.0$ & 1.460 \\
$1000 \mathrm{ppm}$ MOPE & $1.1 \mathrm{R}+7 \mathrm{Y}=12.5$ & 1.460 \\
$200 \mathrm{ppm}$ WOPE & $1 \mathrm{R}+6 \mathrm{Y}=11.0$ & 1.460 \\
$400 \mathrm{ppm}$ WOPE & $1.1 \mathrm{R}+6 \mathrm{Y}=11.5$ & 1.460 \\
$600 \mathrm{ppm}$ WOPE & $1.2 \mathrm{R}+7 \mathrm{Y}=13.0$ & 1.460 \\
$800 \mathrm{ppm}$ WOPE & $1.2 \mathrm{R}+7 \mathrm{Y}=13.0$ & 1.458 \\
$1000 \mathrm{ppm}$ WOPE & $1.1 \mathrm{R}+7 \mathrm{Y}=12.5$ & 1.459 \\
$200 \mathrm{ppm}$ BHT & $1 \mathrm{R}+5 \mathrm{Y}=10.0$ & 1.460 \\
\hline
\end{tabular}

MOPE = Methanol Orange Peel Extract; WOPE= Water Orange Peel Extract, BHT= Butylated hydroxyl toluene

$\mathrm{R}=$ Red Slide; $\mathrm{Y}=$ Yellow Slide

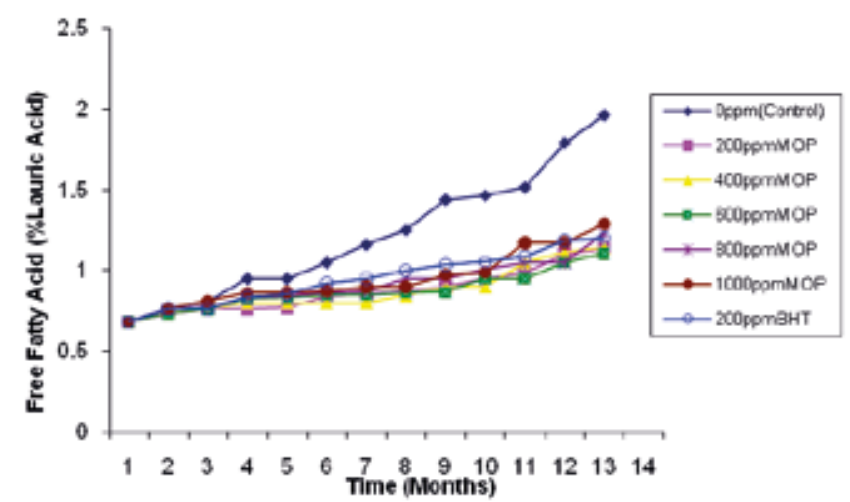

Figure1: Free Fatty Acid of Refined Palm Kernal Oil stored with Nethanol Orange Peel (MOP) Extract and BHT fer twelve months the FFA of oil containing WOP extract was lower than the FFA of oil containing 200 ppm BHT. The FFA of the oil sample containing WOP extract slightly decreased as the concentration of WOP extract increased in the oil. Hence increase in the extract concentration in the oil reduces the rate at which the oil undergoes hydrolytic rancidity.

The acid value (AV) of refined palm kernel oil stored with methanol orange peel (MOP) extract and BHT for twelve months is revealed in Figure 3. The trend observed resemble that of Figure III. above. It was clearly observed that in the first nine months of storage, all the varying concentrations of MOP extract were effective in lowering the acid value of refined palm kernel oil than 200 ppm BHT. The capability of MOP extract to reduce acid value of RPKO slightly increased as the concentration of the extract increased. Figure IV. 

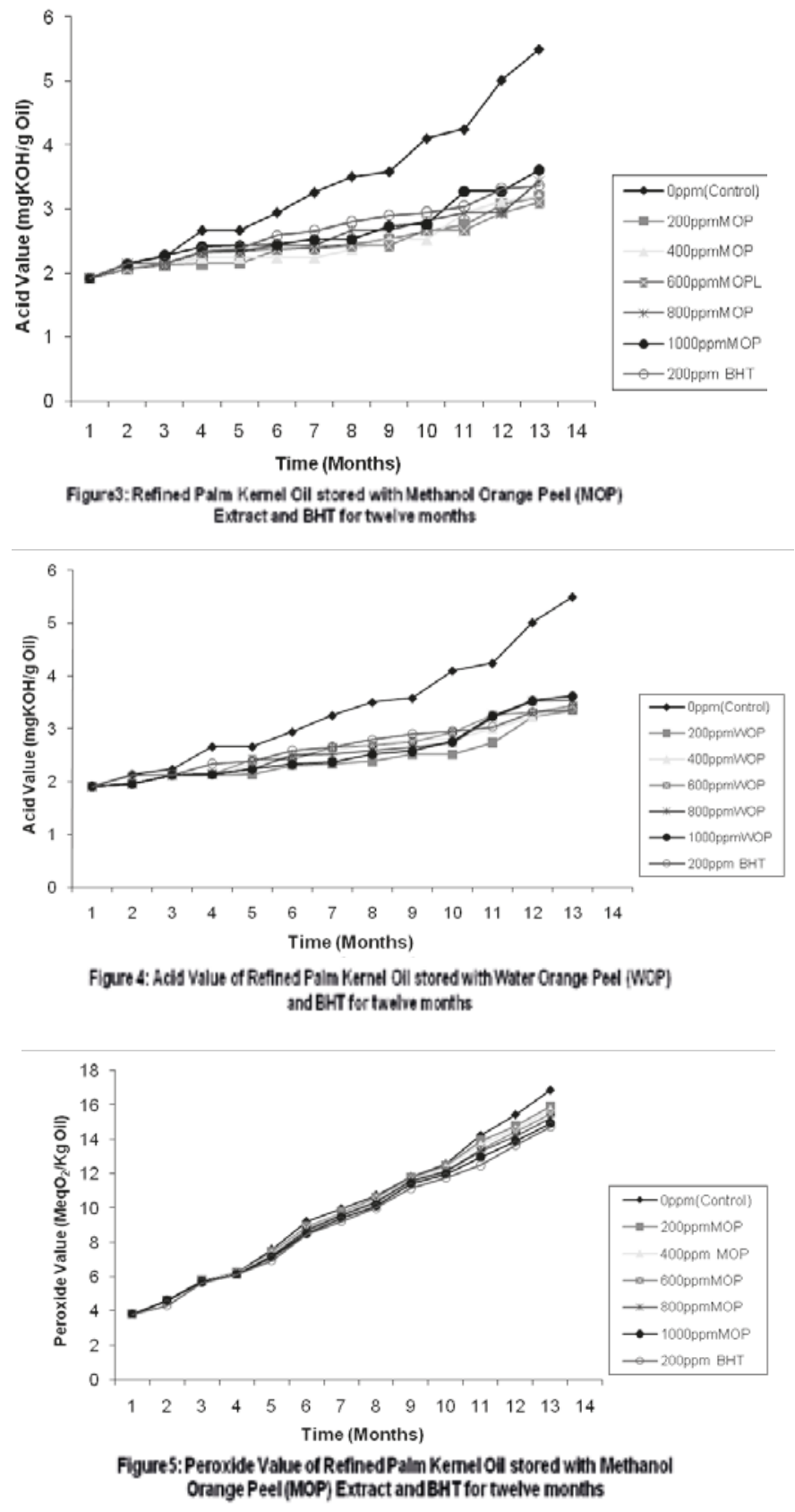

depicts acid value of refined palm kernel oil stored with water orange peel (WOP) extract and BHT for twelve months. Throughout the twelve months of storage the acid value of RPKO that contained no additive was higher than oil samples that contained additives (extracts and BHT). As the concentration of WOP extract increased in the oil sample, the acid value of the oil decreased remarkably. In the first nine months of storage, orange peel extracts were more effective than 200 ppm BHT in reducing the acid value of RPKO.

Figure V. reveals the peroxide value (PV) of refined palm kernel oil stored with methanol orange peel (MOP) extract

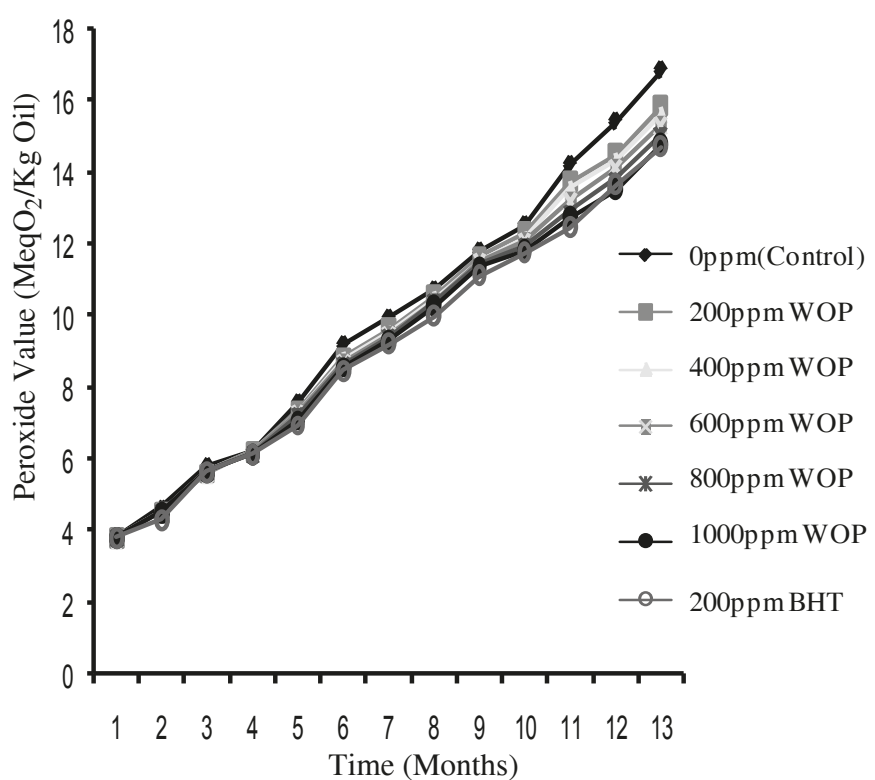

Figure 6: Peroxide Value of Refined Palm Kernel Oil stored with Water Orange Peel (WOP) Extract and BHT for twelve months

and butylatedhydroxytoluene (BHT) for twelve months. The trend observed was in agreement with the observations reported by Amir et al. 2005 for the plot of peroxide value of soybean oil mixed with pistachio hull extract; Zalejiska-Fiolka 2001 for the plot of peroxide value of oxidation process of edible oils mixed with garlic extract and Maskan and Karatas 1998 for the plot of peroxide value of pistachio nut. All the additives slightly lowered peroxide value of RPKO. MOP extract at all the varying concentrations were not as effective as $200 \mathrm{ppm}$ BHT in lowering peroxide value of refined palm kernel oil. Peroxide value of refined palm kernel oil stored with water orange peel (WOP) extract and butylatedhydroxytoluene (BHT) for twelve months is shown in Figure 6. RPKO mixed with 200 ppm -1000 ppm WOP extract had higher peroxide value than oil sample mixed with 200 ppm BHT. Generally, the peroxide value of refined palm kernel oil gradually decreased as the concentration of MOP and WOP extracts increased in the oil sample for the twelve months of storage.

Table II reveals the mean values of FFA, AV and PV of refined palm kernel oil stored with varying concentrations of methanol and water orange peel extract and 200 ppm BHT for a period of twelve months. The addition of methanol and water extracts of orange peel to RPKO resulted in lowering FFA and AV of oil sample than 200 ppm BHT. Free fatty acid and acid value of any lipid are measure of hydrolytic rancidity (Cocks and Rede, 1966, Ihekoronye and Ngoddy, 1985; Farag et al. 2003; Farag et al. 2006; Rehab 2010). The higher the value of FFA and AV of any lipid, the higher the degree of hydrolytic rancidity that set-in (Ihekoronye and Ngoddy, 1985; Arawande and Amoo, 2009). The FFA and 
AV of RPKO containing all varying concentrations of both MOP and WOP extracts were not significantly different at $\mathrm{P}<0.05$ when compared with 200 ppm BHT but it was significantly different at $\mathrm{P}<0.05$ in comparison with the was higher than that of 200 ppm BHT. But the antioxidant activity of both extracts against oxidative rancidity in RPKO was relatively lower than 200 ppm BHT.

Table II: Mean value of some selected quality properties of refined palm kernel oil stored with varying concentration of methanol and water orange peel extract and $200 \mathrm{ppm}$ BHT over a period of twelve months

\begin{tabular}{|c|c|c|c|}
\hline $\begin{array}{c}\text { Concentration of } \\
\text { Additive }\end{array}$ & $\begin{array}{c}\text { *Free Fatty Acid } \\
(\text { FFA) } \\
(\% \text { Lauric acid })\end{array}$ & $\begin{array}{c}\text { *Acid Value } \\
\text { (AV) } \\
(\mathrm{mg} \mathrm{KOH} / \mathrm{g} \mathrm{Oil})\end{array}$ & $\begin{array}{c}\text { *Peroxide Valuel } \\
\text { (PV) } \\
\text { (meq O2/Kg Oil) }\end{array}$ \\
\hline 0 ppm (No additive) & $1.214 \pm 0.401 b$ & $3.368 \pm 1.107 \mathrm{~b}$ & $9.913 \pm 14.183 b$ \\
\hline 200 ppm MOPE & $0.873 \pm 0.140 \mathrm{a}$ & $2.445 \pm 0.391 \mathrm{a}$ & $9.683 \pm 3.961 \mathrm{ab}$ \\
\hline 400 ppm MOPE & $0.873 \pm 0.143 \mathrm{a}$ & $2.445 \pm 0.400 \mathrm{a}$ & $9.589 \pm 3.896 \mathrm{ab}$ \\
\hline 600 ppm MOPE & $0.871 \pm 0.119 a$ & $2.439 \pm 0.333 \mathrm{a}$ & $9.483 \pm 3.813 \mathrm{a}$ \\
\hline 800 ppm MOPE & $0.911 \pm 0.148 \mathrm{a}$ & $2.552 \pm 0.413 b$ & $9.411 \pm 3.746 \mathrm{a}$ \\
\hline 1000 ppm MOPE & $0.942 \pm 0.175 a$ & $2.638 \pm 0.488 \mathrm{a}$ & $9.277 \pm 3.638 \mathrm{a}$ \\
\hline 200 ppm WOPE & $0.871 \pm 0.159 \mathrm{a}$ & $2.439 \pm 0.444 \mathrm{a}$ & $9.595 \pm 3.937 \mathrm{ab}$ \\
\hline 400 ppm WOPE & $0.922 \pm 0.171 \mathrm{a}$ & $2.581 \pm 0.477 \mathrm{a}$ & $9.483 \pm 3.844 \mathrm{a}$ \\
\hline 600 ppm WOPE & $0.936 \pm 0.184 \mathrm{a}$ & $2.621 \pm 0.515 \mathrm{a}$ & $9.401 \pm 3.756 \mathrm{a}$ \\
\hline 800 ppm WOPE & $0.925 \pm 0.195 \mathrm{a}$ & $2.592 \pm 0.546 a$ & $9.300 \pm 3.661 \mathrm{a}$ \\
\hline 1000 ppm WOPE & $0.916 \pm 0.204 a$ & $2.567 \pm 0.570 \mathrm{a}$ & $9.199 \pm 3.572 \mathrm{a}$ \\
\hline 200 ppm BHT & $0.948 \pm 0.164 \mathrm{a}$ & $2.654 \pm 0.458 \mathrm{a}$ & $9.100 \pm 3.564 \mathrm{a}$ \\
\hline
\end{tabular}

NOTE: Within each column, mean values followed by the same superscript are not significantly different at $\mathrm{P}<0.05$ level according to Duncan Multiple Range Test (DMRT).

*Mean Value of Quality Properties \pm Standard Deviation.

MOPE $=$ Methanol Orange Peel Extract; WOPE $=$ Water Orange Peel Extract, BHT= Butylated hydroxyl toluene

control which contained no additive. The Peroxide Values of RPKO containing methanol and water orange peel extracts at varying concentration were slightly higher than RPKO that contained 200 ppm BHT. The PV of RPKO containing additives was significantly different at $\mathrm{P}<0.05$ from $\mathrm{PV}$ of RPKO which contained no additive. The peroxide value of oil samples decreased gradually as the concentration of additives increased. Peroxide value is a measure of oxidative rancidity of oils and the lower the PV value the better is the oil quality (Ihekoronye and Ngoddy, 1985; Rossel, 1994, Amir et.at, 2005) Water and methanol orange peel extracts are not as effective as 200 ppm BHT in combating oxidative rancidity of RPKO.

\section{Conclusion}

Both methanol and water extracts of orange peel had pronounced antioxidant activity against hydrolytic and oxidative rancidity of refined palm kernel oil stored in white transparent plastic bottles. The antioxidant activity of both extracts against hydrolytic rancidity in refined palm kernel oil

\section{References}

Amir HG, Mohsen B and Mohammed AS (2005), Antioxidant activity and total phenolic compound of Pistachio (Pistachio Vera) hull extracts, Food Chemistry 92: $521-525$

Anonymous. (2011), Health properties of Orange peel: Green living pips and Orange peel tips.

AOCS (2004), Official and Tentative Method of the American Oil Chemists Society, 5th ed. (American Oil Chemists Society Champaign II, US) 2004, Method cd 8:53.

Arawande JO and Abitogun AS (2009), Comparative studies of antioxidant potential of citric acid and methanolic extract of cabbage star leaf on crude palm kernel oil, $J$. Chem. Soc. Nigeria 34(1): 54-57.

Arawande JO and Amoo IA (2009), Stability of refined soybean oil stored in various conditions. Pakistan J. Sc. Ind. Res. 52(6): 303-306. 
Arawande JO and Komolafe EA ( 2010), Antioxidative potential of Banana and Plantain peel extracts on crude palm oil. Ethnotanical Leaflet 14: 559-569

Arawande JO and Seyifunmi OE (2010), Effect of citric -acid (food grade) on the quality characteristics of refined palm kernel oil stored in different containers. Journal of Chemical Society of Nigeria 35(1): 53-56.

Bernardini E (1973). Oil and Fat Technology. ( House Technologie S.R.L. Rome) 1973, pp. 68-85

Carrasquero A, Salazar M and Nava PB (1998), Antioxidant activity of grape seed extract on vegetable oils, J. Sc. Food and Agric., 77: 436-467.

Cocks LV and Rede CV (1966), Laboratory Handbook of Oil and Fat Analyst. (Academic Press, New York) 1966, pp. 67-70.

Enrol D, Mechmet U, Ferda C, Dimitra D, Gulhan VU, Mosschos P and Atalay S (2004), Antimicrobial and antioxidantive activities of essential oils and methanol extract of Saliva cryptantha (Montbret et Aucherex Benth) and Saliva multicaulis (Vahl), J. Food Chemistry, 84: 519-525.

Farag RS, El-Baroty GS and Amany MB (2003), The influence of phenolic extracts obtained from the olive plants (cvs Picual and Kronakii) on the stability of Sunflower Oil. J. Food Sc. Tech. 38: 81-87.

Farag RS, Mohamoud EA, Basuny AM and Rehab FMA (2006), Influence of crude Olive leaf extract juice on rat liver and kidney functions. Int. J. Food and Tech. 41: $1-10$.

Frankel E.N. (1996), Antioxidants in food and their impact on food quality. Food Chemistry 57: 51-55

Gunstone FD and Norris FA (1983), Lipids in Foods: Chemistry, Biochemistry and Technology. (Pergamon Press Ltd. England) 1983, pp. 58-75.

Hamilton RJ, KaluUC, Padley FB and Pierce H (1997), Chemistry of free radicals in lipids. Food Chemistry 60: 193-199.

Ihekoronye AI and Ngoddy PO (1985), Integrated Food Science and Technology for the Tropics, (Macmillan Publisher Ltd. London) 1985, pp. 709-719.

Madhavi DL, Deshpannde SS and Salunkhe DK (1996), Food Antioxidants: Technological, Toxicological and Health Perspectives. (Marcel Dekker, Inc. New York) 1996, pp. 2-7

Malecke M (2002), Antioxdant properties of the unsaponifiable matter isolated from tomato seeds, oat grains and wheat germ oil. Food Chemistry. 79: 327-330.

Maskan M and Karatas S (1998), Fatty acid oxidation of Pistachio nuts stored under various conditions and different temperature, J. Sci. Food Agric., 77: 334-340.

More E (1990), Vegetable Fats/Oils. Castobery. 2-3.

Murkovic M (2003), Phenolic compounds. In: CaballeroB., Tingo L.C. \& Finglas P.M. (eds).Encylopedia of Food Sciences 2nd ed. (Oxford Elsevier Science Ltd.) 2003, pp. 4507-4515.

Navar WW (1996), Lipids. In: Fennema, O.R.(Ed.) Food Chemistry. 3rd edition. (Marcel Dekker, Inc. New York) 1996 pp. 225-319.

Anomymous NIS(2000), Nigeria Industrial Standards for Refined Palm Kernel Oil. NIS 289: 3-4.

Oboh G and Rocha JBT (2006), Antioxidant in Foods: A New Challenge for Food Processors. (Nova Science Publishers Inc.) 2006, pp. 2-4, 16-42

Rehab FMA (2010), Improvement the stability of fried sunflower oil by using different levels of Pomposia (Syzyyium cumini). Electronic Journal of Environmental, Agricultural and Food Chemistry 9(2): 396-403.

Rossel JB (1994), Measurement of Rancidity. In: J.C.Allen and R.J.Hamiton (Eds.), Rancidity in Food, 3rd ed. (Balckie U.K) 1994, pp. 56-69

Salma R and Tranveer AC (2005), Intramolecular fatty acids distribution in the triglycerides of Hordeuum vulgare. Pakistan J. Ind. Res. 48(6): 389-392.

SAS (2002), Statistical Analysis System Proprietary Software Release 8.3. SAS Institute Inc. Carry NC.

Wanasundara UN and Shahidi F (1998), Antioxidant and pro-oxidant activity of green tae extracts in marine oils. Food Chemistry 63: 335-342.

Anomymous, Wikipedia (2011), PalmOil- Wikipedia. http://en. wikipedia.org/wiki/palmoil. Retrieved 26/11/2012.

Zaleji-Fiolka J (2001), The influence of Garlic extract on the oxidation process of edible oils, La Rivista Italian Delle Sostanza Grass, 78: 343-348

Received: 4 October 2012; Revised: 9 April 2014; Accepted: 22 December 2014. 